GSA Data Repository 2016074

\title{
Translating taxonomy into the evolution of conodont feeding ecology
}

\author{
Carlos Martínez-Pérez ${ }^{1,2}$, Emily J. Rayfield ${ }^{2}$, Hector Botella ${ }^{1}$,and Philip C.J. Donoghue ${ }^{2}$ \\ ${ }^{1}$ Department of Geology, University of Valencia (Valencia, Spain); Carlos.Martinez- \\ Perez@uv.es; Hector.Botella@uv.es. \\ ${ }^{2}$ School of Earth Sciences, University of Bristol, UK; Phil.Donoghue@bristol.ac.uk; E. \\ Rayfield@ bristol.ac.uk.
}

\section{MATERIALS AND METHODS: FURTHER DETAILS}

Our research comprised of two principal stands: (1) occlusal and microwear analyses to develop the functional model for the genus; and (2) Finite Element analysis of different species of the genus informed by the occlusal and microwear analyses previously performed.

The description of the functional model was based on both articulated clusters and disarticulated P1 elements of Polygnathus xylus xylus from the Upper Devonian of the Canning Basin, Western Australia (Nicoll, 1985). Clusters including pairs of $\mathrm{P}_{1}$ elements were characterized using synchrotron radiation X-Ray Tomography (SRXTM), at the X02DA TOMCAT beamline of the Swiss Light Source, Paul Scherrer Institute (Villigen, Switzerland), using a 10x objective, exposure time at $17 \mathrm{keV}$ of 300 ms, acquiring 1501 projections equiangularly over $180^{\circ}$. Isotropic voxel dimensions are $0.65 \mu \mathrm{m}$. Projections were post-processed and rearranged into flat- and dark-fieldcorrected sinograms, and reconstruction was performed on a 60-core Linux PC farm using a Fourier transform routine and a regridding procedure (Marone and Stampanoni 2012). The reconstructed files were analysed and manipulated using AVIZO v.7.1 
(VSG), allowing us to extract accurate 3D virtual models of the articulated clusters, from which enlarged physical pairs (x150) were created using a Makerbot ${ }^{\circledR}$ Replicator 2 printer. These physical models were used to inform our digital occlusal analysis with GEOMAGIC STUDIO v. 12 (Geomagic, USA). The occlusal model was corroborated with the microwear analysis of isolated $\mathrm{P}_{1}$ elements of Polygnathus xylus xylus from the same samples of the clusters. The microwear data was acquired from both the occlusal and non-occlusal sides of the blades and platforms using a Scanning Electron Microscope (Hitachi S-3500N) hosted at the University of Bristol, prior coated with gold, and viewed with secondary electron mode, with an acceleration voltage of 10 to $15 \mathrm{kV}$. All the specimens are deposited at the Australian Bureau of Mineral Resources within the Commonwealth Palaeontological Collection (CPC).

Our functional interpretation of Polygnathus $\mathrm{P}_{1}$ elements was based on FE Analysis, a conventional engineering technique used to analyse the stress and strain within biological complex shapes. Following the methodology described in MartínezPérez et al. (2014), the 3D models of the $\mathrm{P}_{1}$ elements, derived from the Polygnathus cluster, were used to interpret the occlusal model for $\mathrm{P}_{1}$ elements of species of the genus. We used the results of the occlusal analysis to inform the position of our 2D FE analyses, in which the most constrained region of the platforms coincides with the cross-sections that have been used to characterise the early evolution of Polygnathus through the Pragian-Emsian, viz. P. pireneae, P. kitabicus, P. excavatus, P. gronbergi, $P$. nothoperbonus and $P$. inversus (Yolkin et al., 1994: Text-fig, 2). We digitised these cross-sectional outlines using tpsDig, before imported the resulting files into COSMOSM (SRAC, California and CenitDesktop, U.K.) for the FE analysis. Following Martínez-Pérez et al. (2014), we undertook a 2D-FE analysis based on 6 three-noded triangular finite elements models, with the entire functional surface loaded, simulating 
the presence of food particles between the elements and therefore an even distribution of the loads across the oral surface. The models were anchored at the basal cavity area with 6 degrees of freedom (Fig. DR1).

Following Jones et al. (2012), and assuming a comparable histology for conodont crown enamel-like tissue to the true enamel, we applied homogeneous material properties to the models: Young's modulus $=60 \mathrm{GPa}$; Poisson ratio $=0.23$ and density $=2.5 \mathrm{e} 3 \mathrm{~kg} / \mathrm{m} 3$. To simulate occlusion loads, $1 \mathrm{~N}$ was distributed across the nodes of the functional oral surface (see above). The loads applied were estimated based on the measurements of Jones et al. (2012) and Martínez-Pérez et al. (2014). However, in order to compare our models, we scaled them to have equal force per surface area to remove the effects of the model size and provide a comparison of stress-strength performance based solely on shape (Dumont et al., 2009). Table 1DR summarizes the number of nodes and elements, the number of total nodes loaded, and the force in Newtons applied per node to the different models. Two simulations, for the dextral and sinistral elements, were developed. However, because the results were effectively mirror images, just the right element stress distribution patterns are described. 2D FE analysis has been demonstrated as an accurate approach to infer the mechanical behavior of the conodont platform. Martínez-Pérez et al. (2014) showed how the stress distribution patterns of the platform correlated with the variation in complexity of the inner microstructure, demonstrating the reliability of this method for studying conodont mechanical behavior.

\section{REFERENCES CITED IN THE SUPPLEMENTARY ONLINE MATERIAL}

Jones, D., Evans, A.R., Siu, K.K.W., Rayfield, E.J., and Donoghue, P.C.J., 2012, The sharpest tools in the box? Quantitative analysis of conodont element functional 
morphology: Proceedings of the Royal Society B: Biological Sciences, v. 279, p. 2849-2854, doi:10.1098/rspb.2012.0147.

Dumont, E.R., Grosse, I.R., and Slater, G.J., 2009, Requirements for comparing the performance of finite element models of biological structures: Journal of Theoretical Biology, v. 256, p. 96-103, doi: 10.1016/j.jtbi.2008.08.017

Marone F. and Stampanoni, M., 2012, Regridding reconstruction algorithm for real-time tomographic imaging: Journal of Synchrotron Radiation, v. 19, p.1029-1037.

Martínez-Pérez, C., Rayfield, E.J., Purnell, M.A., and Donoghue, P.C.J., 2014, Finite elements, occlusion and wear analyses indicate that conodont microstructure is adapted to dental function: Palaeontology, v. 57, p. 1057-1066. doi: 10.1111/pala.12102

Nicoll, R.S., 1985, Multielement composition of the conodont species Polygnathus xylus xylus Stauffer, 1940 and Ozarkodina brevis (Bischoff \& Ziegler, 1957) from the Upper Devonian of the Canning Basin, Western Australia: Bureau of Mineral Resources Journal of Australian Geology and Geophysics, v. 9, p. 133-147.

Yolkin, E.A., Weddige, K., Izokh, N.G., and Erina, M.V., 1994, New Emsian conodont zonation (Lower Devonian): Courier Forschungsinstitut Senckenberg, v. 168, p. 139-157. 


\section{SUPPLEMENTARY FIGURES AND TABLES}

Figure DR1. (A) right conodont element of Polygnathus excavatus showing the general distribution of loads and constrains used in our FE analysis. The 2D FE-analysis was focused on the ventral domain of the $\mathrm{P}_{1}$ element of the six species of Polygnathus, extracting the transversal section from Yolkin et al. (1994). Load conditions were informed by analysis of occlusion and wear, assuming that the loads were distributed across the oral surface simulating the presence of food particles between the right and left elements (vertical arrows; see Martinez-Perez et al., 2014 for further details). The models were anchored at the basal cavity area, at the contact with basal body.

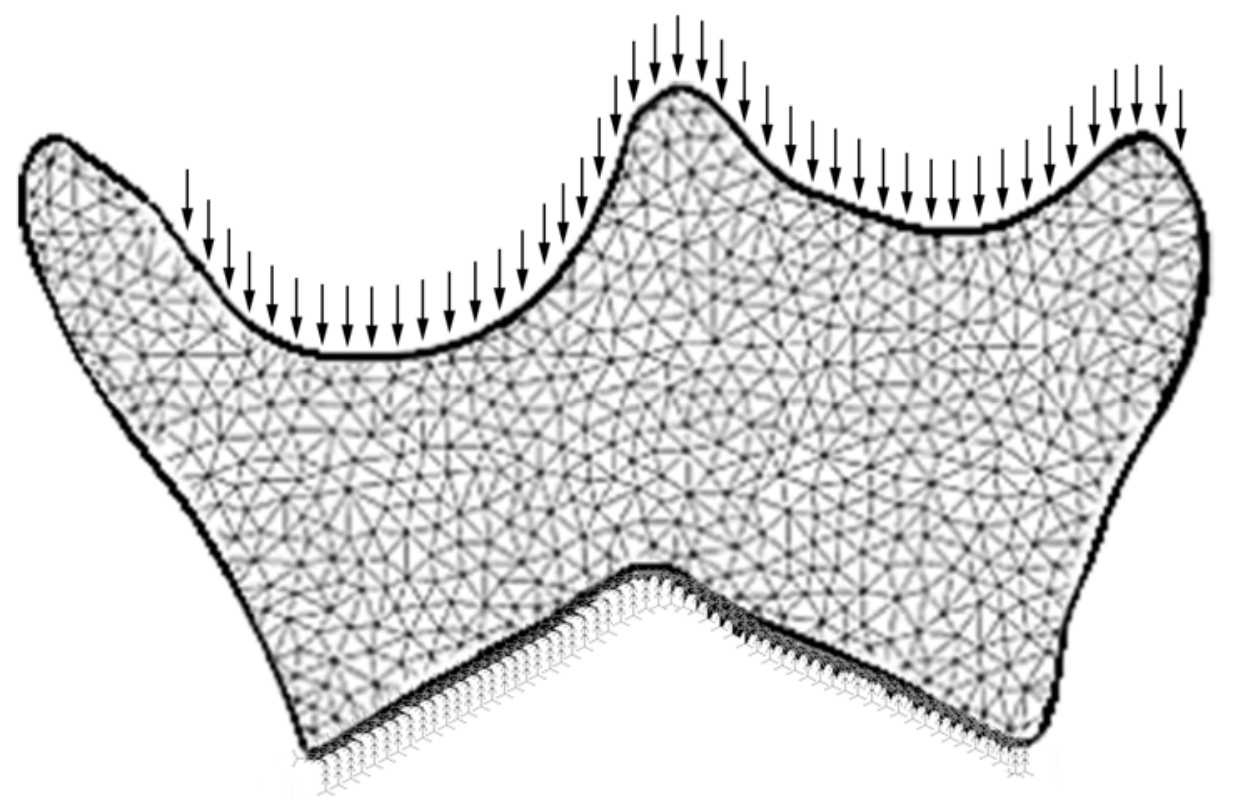


Table DR1. Shows the area and number of nodes and elements of the different Finite Element models. To simulate the occlusion loads, $1 \mathrm{~N}$ was distributed across the nodes of the oral surface based on the measurements of Jones et al. (2012) and Martínez-Pérez et al. (2014). However, in order to compare our models, we scaled the models to have equal force per surface area to remove the effects of the model size. Accordingly the number of total nodes loaded, and the Newtons applied per node in the different scaled models, is shown.

\begin{tabular}{|l|c|c|c|r|r|c|c|}
\hline \multicolumn{1}{|c|}{ Taxon } & Nodes & Elements & Area & Ratio & Total load (N) & nodes & node \\
\hline P. pireneae & 3081 & 5806 & 185968 & 1 & 1 & 99 & 0.01 \\
\hline P. kitabicus & 2529 & 4760 & 192265 & 1.033860664 & 1.033860664 & 110 & 0.0094 \\
\hline P. excavatus & 3191 & 6061 & 208159 & 1.119326981 & 1.119326981 & 121 & 0.0093 \\
\hline P. gronbergi & 2610 & 4905 & 205752 & 1.106383894 & 1.106383894 & 123 & 0.009 \\
\hline P. nothoperbonus & 2510 & 4731 & 192149 & 1.033236901 & 1.033236901 & 120 & 0.0086 \\
\hline P. inversus & 2619 & 4923 & 193888 & 1.042587972 & 1.042587972 & 136 & 0.0077 \\
& & & & & & & \\
\hline
\end{tabular}

